\title{
Rapunzel Syndrome: A Comprehensive Review of an Unusual Case of Trichobezoar
}

\author{
Veena Gonuguntla, MD and Divya-Devi Joshi MD, FAAP
}

An unusual form of bezoar extending from the stomach to the small intestine or beyond has been described as Rapunzel syndrome. Bezoars are concretions in the gastrointestinal tract that increase in size by continuous accumulation of non-absorbable food or fibers. Most bezoars in children are trichobezoars from swallowed hair from the head, dolls, or brushes. Trichobezoars typically cause abdominal pain and nausea, but can also present as an asymptomatic abdominal mass, progressing to abdominal obstruction and perforation. Trichobezoar with Rapunzel syndrome is an uncommon diagnosis in children with less than 40 cases reported. It is predominantly found in emotionally disturbed or mentally retarded youngsters. We present the youngest case of Rapunzel syndrome in the United States, a 5-year-old girl with mental retardation who presented with abdominal pain, vomiting and a non-tender abdominal mass.

Keywords: Abdominal mass; Emotional disturbance; Mental retardation;

Rapunzel syndrome; Trichobezoar

Reprint Requests:

Divya-Devi Joshi MD, MMM

Medical Director

Torrance Hospital IPA

2355 Crenshaw Blvd, Suite 150

Torrance, CA 9050I

E-mail: djoshi@thipa.com

Received: September 5, 2008

Revised: December 5, 2008

Accepted: February 9, 2009

doi: $10.3121 / \mathrm{cmr} .2009 .822$
$\mathrm{B}$

ezoars are concretions of human or vegetable fibers that accumulate in the gastrointestinal tract. The word "bezoar" comes from the Arabic word "bedzehr" or the Persian word "padzhar," meaning "protecting against a poison." At different times in history, bezoars from animal guts were used as precious stones, antidotes to poisons and today as part of traditional Chinese medicine. ${ }^{1}$ The first reference to a bezoar in a human was in 1779 during an autopsy of a patient who died from gastric perforation and peritonitis. ${ }^{2,3}$

In humans, the most common type of bezoar is the trichobezoar, which is mostly made of hair. However, bezoars can also be made of vegetable or fruit fiber (phytobezoars), milk curd (lactobezoars), or any indigestible material.

Trichobezoars, unlike other bezoars, are not associated with alterations in gastrointestinal motility but with underlying psychiatric disorders, and most commonly present in adolescents and during the second decade of life. Rapunzel syndrome is an unusual and rare form of trichobezoar extending into the small intestine. The name "Rapunzel" syndrome comes from the Grimm Brothers' fairy tale of a 12-year-old princess who was shut into a tower with neither stairs nor doors by an enchantress who climbed up the tower's walls with the help of Rapunzel's long tresses. ${ }^{4}$

Most cases of trichobezoar are reported in females, which may be attributed to the traditional long hair in females. One reported male case ate the hair of his sisters. ${ }^{5}$ A cotton bezoar with Rapunzel syndrome was recently reported in an 18-year-old male. ${ }^{6}$ The majority of these cases presented between 13 and 20 years of age. 


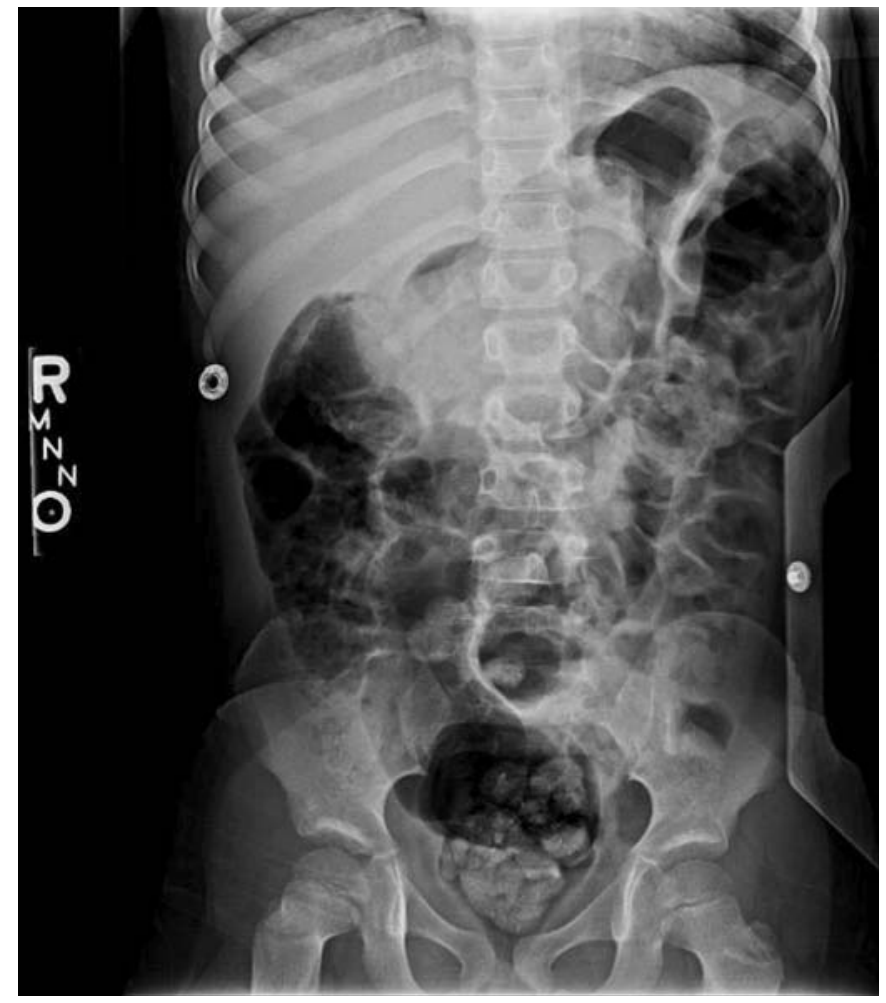

Figure 1. Plain radiograph of the abdomen showing multiple air fluid levels with dilated small intestinal loops and a sizable soft tissue density within the stomach are seen.

We present the youngest documented patient with Rapunzel syndrome in the United States.

\section{Case Report}

A 5-year-old female, born at 25 weeks gestation with bilateral sensorineural deafness and broncho-pulmonary dysplasia, presented to the emergency room with a 1.5 week history of poorly localized abdominal pain and 3 days of postprandial emesis. She would curl up with pain after eating and then feel relief after vomiting. The child appeared to be in some discomfort but was able to communicate by sign language. The mother commented on early satiety and chronically decreased appetite. There was no history of acid reflux, diarrhea, increased flatulence, recent illnesses, or fever. There were no changes in her bowel habits. The child had always been on the lower end of the growth curve with underweight compared to height. Abdominal examination revealed a hard, non-tender, ballotable mass of approximately $10 \mathrm{~cm} \times 6 \mathrm{~cm}$ in the epigastric region extending into the right upper quadrant. She had exaggerated bowel sounds. The rest of the physical examination was normal.

Plain radiograph of the abdomen showed multiple air fluid levels with dilated small intestinal loops and a sizable soft tissue density within the stomach (figure 1). Laboratory workup revealed only concentrated urine and pyuria. Complete blood count, complete metabolic panel, as well as pancreatic enzymes, were normal.
Because of the large size of the abdominal mass and soft tissue density on x-ray, abdominal computed tomography (CT) with contrast was performed with the concern of a possible tumor. The CT confirmed large amounts of mottled material in the stomach, believed to be bezoar extending into the small intestine (figure 2). Gastrotomy was performed the next day and the mass removed in one piece. The $11.5 \mathrm{~cm}$ x $6 \mathrm{~cm} \times 4 \mathrm{~cm}$ mass was found to be a trichobezoar with a tapering tail extending into the small bowel, and was a perfect cast of the stomach, pylorus and duodenal bulb (figure 3). Only on repeated questioning did the mother give a history of occasional trichophagia. On examination, there was no alopecia. When directly asked, the patient admitted that she liked to eat hair. The patient was discharged home 5 days later, having recovered without complications. Psychiatric followup was arranged, where she showed improvement in behavior, which is key to prevent recurrence.

\section{Discussion}

Bezoars are concretions of foreign material in the gastrointestinal tract, mainly the stomach. Bezoars composed of hair or hair-like fibers are called trichobezoars. Most patients with trichobezoars suffer from psychiatric disorders including trichotillomania (pulling out of their own hair) and trichophagia (eating of hair). Only rarely do these patients chew hair from other sources including hair from wigs. It has been estimated that only $1 \%$ of patients with trichophagia develop a trichobezoar. ${ }^{7,8}$ Trichobezoars form when hair strands, escaping peristaltic propulsion because of their slippery surface, are retained in the folds of the gastric mucosa. As more hair accumulates, peristalsis causes it to be enmeshed into a ball. As this ball gets too large to leave the stomach, gastric atony may result. The ball of hair becomes even more matted together and assumes the shape of the stomach, usually as a single solid mass. ${ }^{9,10}$

We assume that the frequent location of these casts in the stomach is due to the holdup by the pylorus and the churning action of the stomach which helps to entangle new hair into

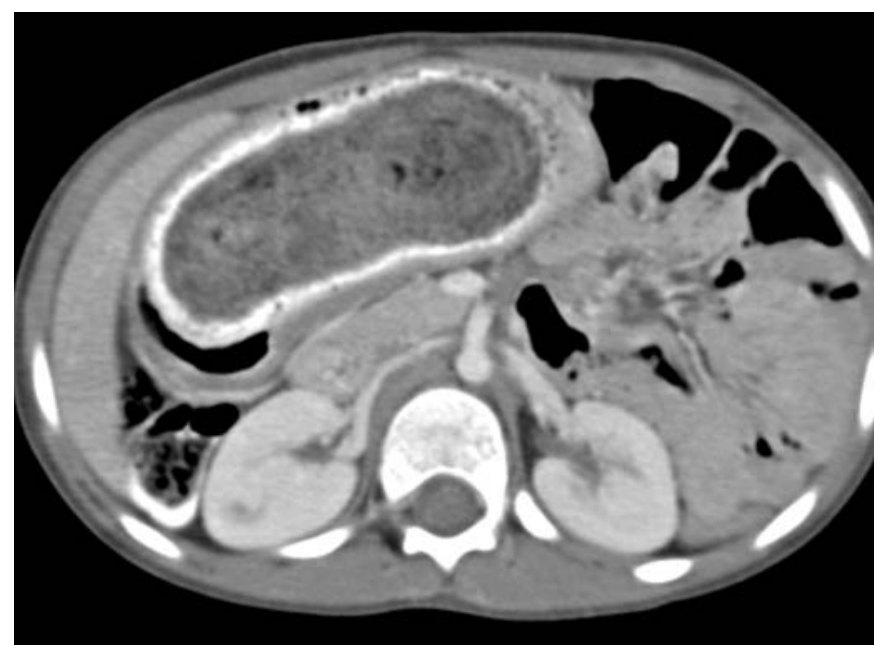

Figure 2. CT showed a $10.8 \mathrm{~cm}$ bezoar, outlined by contrast, in the stomach and extends into the small intestine. 


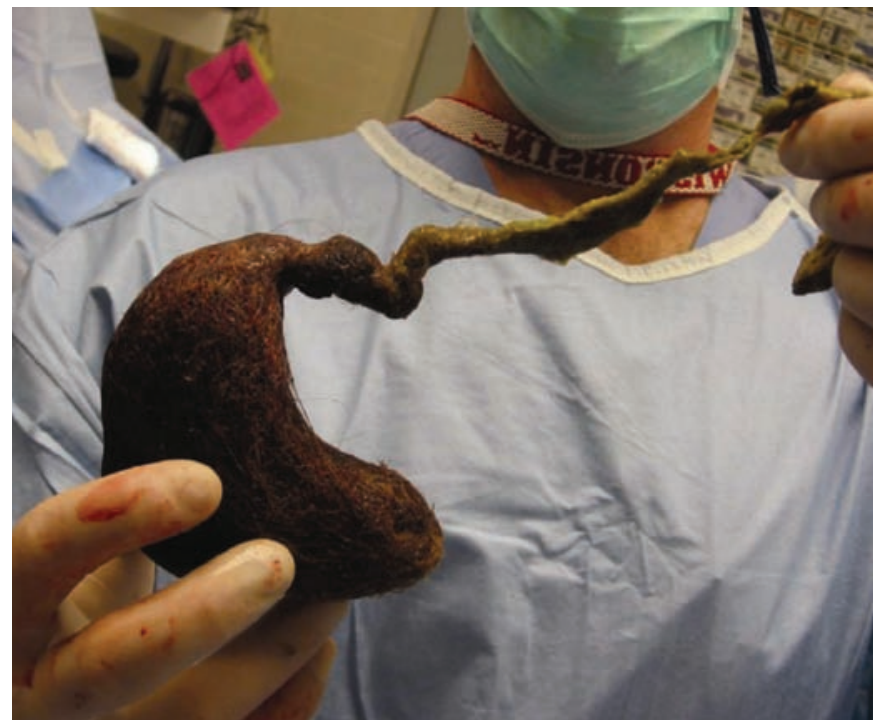

Figure 3. A stomach-shaped trichobezoar with a tapering tail extending into the small bowel is surgically removed en bloc.

the already formed cast. The bezoar takes on a glistening shiny surface from the mucus that covers it. Decomposition and fermentation of fats give the bezoar, and the patient's breath, a putrid smell. ${ }^{11}$ The acidic contents of the stomach denature the hair protein and give the bezoar its black color. ${ }^{12,13}$

Rapunzel syndrome is a rare form of trichobezoar, and various criteria have been used in its description in the literature. Some define it as a gastric trichobezoar with a tail extending up to the ileocaecal junction;,214 some describe it as a simple trichobezoar with a long tail, which may extend up to the jejunum or beyond; and some still define it as a bezoar of any size which can cause intestinal obstruction. ${ }^{2}$

Affected patients occasionally remain asymptomatic for many years. Symptoms develop as the bezoar increases in size to the point of obstruction. Not surprisingly, most of the cases have been reported in countries where women traditionally have long hair. The most common presenting signs are abdominal pain, nausea and vomiting, obstruction, and peritonitis. Less commonly, patients have presented with weight loss, anorexia, hematemesis and intussusception. Complications by a large eroding or obstructing bezoar additionally include gastric ulceration, obstructive jaundice, acute pancreatitis and gastric emphysema. ${ }^{15,16}$ Other malabsorption-related complications include protein-losing enteropathy, iron deficiency, and megaloblastic anemia.

When a bezoar is suspected, the history should focus on trichotillomania and ingestion of items, such as doll or pet hair. Severe halitosis and patchy alopecia provide clues on physical examination. Imaging may show the bezoar as a mass or filling defect. The gold standard for diagnosis is upper gastrointestinal endoscopy. In addition to providing direct visualization, this procedure allows sample taking and potentially therapeutic intervention.
The management and treatment of a bezoar need to encompass removal of the mass and prevention of recurrence by addressing the underlying physical or emotional cause. Depending on its consistency, size and location, bezoar removal may occur via endoscopy or surgery. Endoscopic therapy can be effective for bezoars composed of vegetable matter (phytobezoars) and milk curd (lactobezoars), as they are small in size, but is less likely to be effective for trichobezoars, particularly those that are large $(>20 \mathrm{~cm})$. Specialized bezotomes and bezotriptors (medical devices that pulverize bezoars either mechanically or with acoustic waves) have been used to fragment large and solid trichobezoars. ${ }^{17}$ Surgery is indicated when a very large or solid bezoar causes perforation or hemorrhage, or in the case of Rapunzel syndrome, when there is significant extension of the bezoar. ${ }^{7}$ Surgical removal is accomplished by gastrotomy or enterotomy. Traditionally, a gastric trichobezoar was removed by gastrotomy through an upper midline laparotomy. Since the advent of minimally invasive surgery, surgeons now use laparoscopic techniques for small to moderate-size bezoars. ${ }^{2,18,19}$ Various other methods like extracorporeal shock wave lithotripsy, intragastric administration of enzymes (pancreatic lipase, cellulose), and medications (metoclopramide, acetylcysteine) demonstrate varying success. ${ }^{18}$ Few recurrences are reported after the initial removal of bezoars., ${ }^{3,19,20}$ To decrease recurrence, longterm psychiatric follow-up is advised.

Case reports of children with trichobezoars or Rapunzel syndrome are rare, and many link the trichophagia to early childhood neglect or abuse, ${ }^{21}$ psychiatric conditions, ${ }^{21,22}$ mental retardation ${ }^{23,24}$ or bereavement. ${ }^{2,25}$ Although studies of the pharmacotherapy of trichotillomania remain inconsistent, some patients seem to respond to fluoxetine or other serotonin reuptake inhibitors. ${ }^{26}$ Parental counseling is also a regular part of treatment to prevent recurrence. The patient's longterm prognosis is excellent if behavioral therapy is used to control trichophagia, and psychological/psychiatric follow-up is maintained.

\section{Conclusion}

Trichobezoar, an under-diagnosed entity, has to be considered in the differential diagnosis of abdominal pain and a nontender abdominal mass even in young children, and a history of pica should always be obtained. Small trichobezoars may be extracted by endoscopic fragmentation, gastric lavage, enzymatic therapy or combinations of these approaches. Bezoars like Rapunzel syndrome, on the other hand, need surgical removal.

Many of these patients have psychiatric pathology with emotional problems, family discord, and history of neglect or mental retardation. Counseling by a psychiatrist is an important part of management to prevent recurrence. In young girls with psychiatric history who present with abdominal pain, vomiting or abdominal mass, bezoars/Rapunzel syndrome should be considered in the differential diagnosis. 


\section{Acknowledgments}

The authors wish to thank Dr. Charles McGill, pediatric surgeon, and Dr. Adrienne Cruz, pediatric hospitalist, for their assistance with this case. The authors also thank Marshfield Medical Research Foundation for its support through the assistance of Alice Stargardt in preparing this manuscript for submission.

\section{References}

1. Wang C, Zhao X, Mao S, Wang Y, Cui X. Management of SAH with traditional Chinese medicine in China. Neurol Res 2006;28:436-444.

2. Naik S, Gupta V, Naik S, Rangole A, Chaudhary AK, Jain P, Sharma AK. Rapunzel syndrome reviewed and redefined. Dig Surg 2007;24:157-161

3. Vaughan ED Jr, Sawyers JL, Scott HW Jr. The Rapunzel syndrome. An unusual complication of intestinal bezoar. Surgery 1968;63:339-343.

4. Grimm Brothers: Rapunzel. Translated by Godwin-Jones R. Richmond, Virginia Commonwealth University Department of Foreign Languages, 1994-1999.

5. Hirugade ST, Talpallikar MC, Deshpande AV, Gavali JS, Borwankar SS: Rapunzel syndrome with a long tail. Indian J Pediatr 2001;68:895-896.

6. Emre AU, Tascilar O, Karadeniz G, Irkorucu O, Karakaya K, Comert M. Rapunzel syndrome of a cotton bezoar in a multimorbid patient. Clinics 2008; 63:284-288. Available at: http://www.scielo.br/pdf/clin/v63n2/a21v63n2.pdf. Accessed December 5, 2008.

7. Phillips MR, Zaheer S, Drugas GT. Gastric trichobezoar: case report and literature review. Mayo Clin Proc 1998;73: 653-656.

8. Irving PM, Kadirkamanathan SS, Priston AV, Blanshard C. Education and imaging. Gastrointestinal: Rapunzel syndrome. J Gastroenterol Hepatol 2007;22:2361.

9. Pace AP, Fearne C. Trichobezoar in a 13 year old male: a case report and review of literature, Malta Med J 2003;15:39-40.

10. Deslypere JP, Praet M, Verdonk G: An unusual case of the trichobezoar: the Rapunzel syndrome. Am J Gastroenterol 1982;77:467-470.

11. Sidhu BS, Singh G, Khanna S: Trichobezoar. J Indian Med Assoc 1993;91:100-101.

12. Sharma V, Sahi RP, Misra NC. Gastro-intestinal bezoars. J Indian Med Assoc 1991;89:338-339.

13. O’Sullivan MJ, McGreal G, Walsh JG, Redmond HP. Trichobezoar. J R Soc Med 2001;94:68-70.

14. Kaspar A, Deeg KH, Schmidt K, Meister R. [Rapunzel syndrome, an rare form of intestinal trichobezoars] Klin Padiatr 1999;211:420-422.

15. Jiledar, Singh G, Mitra SK. Gastric perforation secondary to recurrent trichobezoar. Indian J Pediatr 1996;63:689-691.

16. Klipfel AA, Kessler E, Schein M. Rapunzel syndrome causing gastric emphysema and small bowel obstruction. Surgery 2003;133:120-121.

17. Wang YG, Seitz U, Li ZL, Soehendra N, Qiao XA. Endoscopic management of huge bezoars. Endoscopy 1998;30:371-374.

18. Groenewald CB, Smoot RL, Farley DR. A football-sized gastric mass in a healthy teen. Contemp Surg 2006;62:531-534.

19. Eryilmaz R, Sahin M, Alimoğlu O, Yildiz MK. [A case of Rapunzel syndrome]. Ulus Travma Acil Cerrahi Derg 2004;10:260-263.

20. Memon SA, Mandhan P, Qureshi JN, Shairani AJ. Recurrent Rapunzel syndrome - a case report. Med Sci Monit 2003;9:CS92-CS94.
21. Gockel I, Gaedertz C, Hain HJ, Winckelmann U, Albani MI, Lorenz D. [The Rapunzel syndrome: rare manifestation of a trichobezoar of the upper gastrointestinal tract.] Chinurg 2003;74:753-756.

22. Sharma NL, Sharma RC, Mahajan VK, Sharma RC, Chauhan D, Sharma AK. Trichotillomania and trichophagia leading to trichobezoar. J Dermatol 2000;27:24-26.

23. Schulte-Markwort M, Bachmann M, Riedesser P: [Trichobezoar in a 16-year old girl. Case report and review of the literature.] Nervenarzt 2000;71:584-587.

24. Ramadan N, Pandya NA, Bhaduri B. A Rapunzel with a difference. Arch Dis Child 2003;88:264.

25. Duncan ND, Aitken R, Venugopal S, West W, Carpenter R. The Rapunzel syndrome. Report of a case and review of the literature. West Indian Med J 1994;43:63-65.

26. Swedo SE, Leonard HL, Rapoport JL, Lenane MC, Goldberger EL, Cheslow DL. A double-blind comparison of clomipramine and desipramine in the treatment of trichotillomania (hair pulling). N Engl J Med 1989;321: 497-501.

\section{Author Affiliations}

Veena Gonuguntla, MD

Department of Pediatrics

Marshfield Clinic

1000 North Oak Avenue

Marshfield, WI 54449

Divya-Devi Joshi, MD, MMM

Director, Pediatric Hematology/Oncology,

Pediatric Residency

Department of Pediatrics

Marshfield Clinic

1000 North Oak Avenue

Marshfield, WI 54449

Current address:

Medical Director

Torrance Hospital IPA

2355 Crenshaw Blvd, Suite 150

Torrance, CA 90501 